\title{
Comparision of Lateral Sphincterotomy with Glyceral Nitrate 0.2\% / Diltiazem 2\%Local Application in Chronic Fissure in Ano
}

\author{
Authors \\ Rajeev.N (MS), Raghunandan (MS) \\ Dr.B.R.Ambedkar Medical College and hospital \\ Email:drjeevs@gmail.com
}

\begin{abstract}
Background and Objectives: Anal fissures are commonly encountered in routine general surgical practice. Developments in understanding of anatomy,physiology and itsresponse to GNT/Diltiazemhas resulted in new conservative approach.In this study we compare the two modalities of treatment in chronic fissure in ano.

Methods: In the study 80 patients of chronic fissure in ano was treated conservatively with0. 2\% GTN/2\% Diltiazem and lateral sphincterotomy based on the patient preference.The patients were followed up for 5 to 6 weeks for symptomatic relief and healing of fissure and the results compared.

Results: 1. The fissure healed completely in 46 patients with Diltiazem 2\%/NTG0.2\% application twice daily with Sitz bath.2. In 25 patients treated with surgery (Internal Lateral Anal Sphincterotomy), the fissure healed completely.3. The mean duration required for healing of fissure was 5.37weeks in Diltiazem/NTG group and 4 weeks in Internal sphincterotomy group.4.There were no side effects after Diltiazem/NTG therapy, 8 patients treated with sphincterotomy had pain in immediate post-op periods subsided with analgegics.

Conclusion: Comparision between Diltiazem/NTG gel and Internal sphincterotomy did not show any difference in pain relief and fissure healing. But the time taken for healing was less in surgical group compared to conservatively managed group. Conservative treatment is equally efficacious as surgical treatment in this study.
\end{abstract}

\section{METHODOLOGY}

\section{Methods of collection of data}

Cases attending the surgery OPD with complaints of painful defecation with or without bleeding per rectum were considered for the study.A detailed history and per rectal examination was done to diagnose chronic fissure in ano.Patients were explained about the treatment modalities and the patients opted for conservative management (chemicalsphincterotomy) were prescribed as all odd numbers with NTG and even numbers with Diltiazem, those who opted for surgery underwent lateral sphincterotomy. Conservative management involved local application of $2 \%$ Diltiazem/NTG twice daily for 5-6 weeks. Surgical mode of management was lateral sphincterotomy. Both groups were advised plenty of oral fluids, high fibre diet, laxatives and Sitz bath.Follow up of the patients is done by history and per rectal examination to assess the efficacy of treatmentcomplaints like pain, bleeding, sphincteric spasm, discharge per anus and incontinence was noted. 


\section{INCLUSION CRITERIA}

1. Both sex, with age $>18$ yrs with fissure.

2. Associated with pain, spasm of internal sphincter with or without sentinel pile.

3. Cases which were regular for post treatment follow-up.

4. Patients willing to be part of this study.

\section{EXCLUSION CRITERIA}

1. Fissure with TB, AIDS, Crohn's disease.

2. Fissure with complication-abscess or fistula

3. Not willing for follow up

4. Not willing to be a part of this study

\section{RESULTS}

80 patients with various symptoms of fissure in ano were taken for study. All the data were analysed as par the performa chart.

\section{Age incidence}

\begin{tabular}{|l|l|l|}
\hline No of Patients & Age Group & Percentage \\
\hline 3 Patients & $<20$ & $3.75 \%$ \\
\hline 30 patients & $20-30$ & $37.5 \%$ \\
\hline 18 patients & $31-40$ & $22.5 \%$ \\
\hline 18 patients & $41-50$ & $22.5 \%$ \\
\hline 8 patients & $51-60$ & $10 \%$ \\
\hline 3 patients & $>60$ & $3.75 \%$ \\
\hline
\end{tabular}

2. Sex:

\begin{tabular}{|l|l|l|}
\hline Sex & No of Patients & Percentage \\
\hline Females & 36 & $45 \%$ \\
\hline males & 44 & $55 \%$ \\
\hline
\end{tabular}

\section{Symptomatology}

\begin{tabular}{|l|l|l|}
\hline \multicolumn{1}{|c|}{ Symptoms } & No of Patients & Percentage \\
\hline Pain During Defecation & 80 & $100 \%$ \\
\hline $\begin{array}{l}\text { Bleeding Per rectum } \\
\text { with pain }\end{array}$ & 25 & $31.25 \%$ \\
\hline Constipation & 40 & $50 \%$ \\
\hline
\end{tabular}

4.Fissure in ano treatment:

\begin{tabular}{|l|l|}
\hline Therapy & No of Patients \\
\hline GTN & 23 \\
\hline Diltiazem & 23 \\
\hline Surgery & 34 \\
\hline
\end{tabular}

5.Healing in:

Conservative management:

\begin{tabular}{|l|l|l|}
\hline No of Cases & Healed & Non Healed \\
\hline 46 Cases & 40 & 6 \\
\hline
\end{tabular}

Surgery:

\begin{tabular}{|l|l|l|}
\hline No of Cases & Healed & Non Healed \\
\hline 34 Cases & 34 & 0 \\
\hline
\end{tabular}

\section{DISCUSSION}

Anal fissure is a very common problem across the world. It causes considerable morbidity and adversely affects the quality of life. Therefore appropriate treatment is mandatory.

The simplest and most effective way of reducing internal anal sphincter tone is surgery. Lateral internal sphincterotomy is the gold standard in the treatment of chronic anal fissures.

It involves partial division of the internal anal sphincter away from the fissure. Calcium channel blockers have been shown to lower resting anal pressure and promote fissure healing and chemical sphincterotomy is now the first line of treatment in many centres.

In the present study, comparison of different treatment modalities of fissure in ano:

Acute fissure where treated with conservative measures -

- Warm water sitz bath to soothen the pain and reduces the spasm.

- Adequate analgesia is necessary to break the vicious cycle of pain viz. avoidance of defecation for prolonged periods leading to hard stools resulting in further tearing of the anoderm and thereby inviting increased pain. A suitable dose of analgesic consumed half an hour before going for defecation gives a good amount of post defecation pain relief.

- Stool softening is essential .Plenty of oral fluids also help in keeping the stools soft, High-fibre-diet and bulk-forming agents such as Isaphgula; green leafy vegetables and fibrous fruits go a long way in 
increasing the bulk of stool leading to a smooth and swift act of defecation.

- Reassurance and encouragement for not resisting the urge for defecation help prevent hard stools. Later the patient should be encouraged to acquire and maintain a regular bowel habit.

- Application of local anaesthetic cream or gel may help avoid the torture experienced in passage of stools in the patients with acute fissures.

Patients with symptoms of fissure in ano for more than 6 weeks were labelled as having chronic fissure in ano and clinical examination was done to confirm chronic fissure in ano.

Chronic fissure patients were explained about chemical sphincterotomy-Nitroglycerine gel or $2 \%$ Diltiazem gel and lateral internal sphincterotomy and treated as perpatients choice of treatment.

A total of 80 patients of fissure in ano, who presented to surgery opd and / or admitted in Dr B R Ambedkar Medical College and Hospital, Bangalore, were divided into acute and chronic fissure in ano based on history and clinical examination.

Patients with symptoms of fissure in ano for more than 6 weeks were labelled as having chronic fissure in ano and clinical examination was done to confirm chronic fissure in ano. All the data were analysed as per the proforma sheet. In this study the commonest age group affected was 2030 years age group $(37.5 \%)$ and least affected were $>60$ years and $<20$ years age group $(3.75 \%)$. According to J.C. Goligher2 (1984) the disease is usually encountered in young or middle aged adults. In Udwadia $\mathrm{T}$ E series 35 maximum incidence was seen in age group of 31-40 years.

The incidence of fissure in females was slightly lesser than males study and from Bennett and Goligher2 (1962) which says anal fissure is equally common in both the sexes.

Patients with acute fissure were treated conservatively on domiciliary basis and patients with chronic fissure receiving Nitroglycerine gel/
Diltiazem gel therapy underwent treatment on domiciliary basis and were reviewed once a week on outpatient basis. Out of 23 patients undergoing treatment with Nitroglycerine gel, 20 patients healed and 23 patients receiving Diltiazem gel, 20 healed completely.

The mean duration of healing was 5.37 weeks with chemical sphincterotomy and 4 weeks with lateral internal sphincterotomy. Duration for healing with chemical sphincterotomy was comparatively longer than internal sphincterotomy group. Study conducted by J. S. Knight3 et al. (2001) reported a healing rate of $75 \%$ after 8-12 weeks treatment with Diltiazem gel. U. K. Shrivastava6 (2007) reported a healing rate of $80 \%$ with Diltiazem gel in 12 weeks.

In our study no side effects were reported after 6-8 weeks of therapy with Diltiazem gel or Nitrogylcerine gel. In a study conducted by $\mathrm{J}$. Knight 3 et al. 71 consecutive patients were treated with $2 \%$ Diltiazem gel for a median period of 9 weeks. Four patients experienced perianal dermatitis and one patient experienced headache. Study conducted by U. K. Shrivastava reports no side effects in patients treated with Diltiazem gel.6 In a study conducted by G. F. Nash et al. 112 patients were treated with $2 \%$ Diltiazem gel for 6 weeks and were followed up over 2 years. The success rate and satisfaction of topical Diltiazem were each over two thirds. Nearly $80 \%$ of patients reported no adverse effects, and it seems that those complaints attributed to Diltiazem rarely led to reduced compliance.

Two patients in Diltiazem gel group and four patients in Nitrogylcerine group whose fissures did not heal after 8weeks of therapy underwent Internal Sphincterotomy and fissure healed in 4 weeks.

Patients in internal sphincterotomy group underwent surgery under spinal anaesthesia. Postoperative hospital stay was between 1-2 days. In internal sphincterotomy group, fissure healed in 34 out of 34 patients. Mean duration required for healing was 4 weeks. In our study 34(100\%) patients out of 34 underwent internal 
sphincterotomy were free from pain by 6 weeks .Scouten W.R. et al.36 reported pain relief in $98 \%$ of cases after undergoing internal sphincterotomy. Our study shows a healing rate of $100 \%$ after internal sphincterotomy. Adriano Tocchhiet al.37 (2004) reported a healing rate of $100 \%$ with internal Sphincterotomy at the end of 6 weeks post-sphincterotomy review.

In our study no complications were reported in patients undergoing internal sphincterotomy after follow up of patients for 6 weeks. Adriano Tocchhi et al. report no long-term complication after internal sphincterotomy. Patient satisfaction was $96 \%$.

Comparison between Diltiazem gel therapy and Nitroglycerine did not show any difference in pain relief or fissure healing. Non-compliance was uncommon with Diltiazem gel/NTG therapy and were excluded from the study.

In conclusion, patients with acute fissure are treated with conservative management and those with chronic fissure were treated with chemical/lateral internal sphincterotomy. Though fissure healing is comparatively slow with Diltiazem gel/NTG therapy, patients can be avoided from the trauma of surgery and they can take treatment at home. Therefore topical Diltiazem gel/NTG therapy can be advocated as the first line of treatment and surgery should be reserved for patients with relapse and therapeutic failure of prior pharmacological treatment and those who refuse surgery.

\section{REFERENCES}

1. Jonas Marion, Scholefield J.H., Anal fissure and chemical sphincterotomy. Taylor I., Johnson C.D., Recent advances in Surgery. Churchill Livingstone, 24th Edition,2001, pg. 115.

2. John Goligher, Anal Fissure, John Goligher, Surgery of the Anus, Rectum \& Colon. AITBS, 5th Edition, 1992, pg.150.

3. J. S. Knight, M. Birks, R. Farouk, Topical Diltiazem ointment in the treatment of chronic anal fissure. British Journal of Surgery.2001; 88 (4): pg. 553-556.

4. R. Dasgupta, I. Franklin, J. Pitt, P. M. Dawson, Successful treatment of chronic anal fissure with Diltiazem gel. Colorectal Disease; 4: pg. 20-22.

5. Marion Jonas, William Speake, John H. Scholefield, Diltiazem heals Glyceryltrinitrate resistant chronic anal fissures: a prospective study. Diseases of the colon and Rectum. 2002; 45 (8): pg. 1091-1095.

6. U. K. Srivastava, B. K. Jain, Praveen Kumar, Yusuf Saifee, A comparison of the effects of Diltiazem and Glyceryltrinitrate ointment in the treatment of chronic anal fissure: a randomized clinical trial. Surgery Today. 2007; 37 (6): pg. 482-485.

7. E. Carapeti, M. Kamm, B. Evans, R. Phillips, Topical Diltiazem and Bethanechol decrease anal sphincter pressure and heal anal fissures without side effects. Diseases of the Colon and Rectum. 1999; 43 (10): pg. 1359-1362.

8. I. T. Khubchandani, J. F. Reed, Sequelae of internal sphincterotomy for chronic fissure in ano. British Journal of Surgery. 1989; 76 (5): pg. 431-434.

9. John Goligher, Surgical Anatomy and Physiology of the Anus, Rectum and Colon, John Goligher.

10. Surgery of the Anus, Rectum and Colon, AITBS, 5th Edition, 1992,pg. 7.Bannister H.L., Muscle System, Soames R. Gray's Anatomy

11. Lee McGregor, The Large Bowel and Anal Canal, Synopsis of Surgical Anatomy, Decker G.A.G. Varghese Publishing House, 1999, pg. 48.

12. Peter J. Lunniss, The anus and anal canal, Norman S. Williams, Christopher J.K.Bulstrode\& P. Roman O’Connell. Bailey \& Love's Short Practice of Surgery, Hodder Arnold, 25th edition, 2008, pg. 1251-1253. 
13. Heidi Nelson, Robert R. Cima, Anus, Courtney M. Townsend, R. Daniel Beauchamp, B. Mark Evers, Kenneth L. Mattox. Sabiston Textbook of Surgery, Elsevier, 18th edition, 2003, pg.1443.

14. Jennifer K. Lowney\& James W. Fleshman, Jr., Benign disorders of the anorectum, Michael J. Zinner\& Stanley W. Ashley. Maingot's Abdominal Operations, Tata Mc Graw Hill, 11th edition, 2007, pg. 680684.

15. Harry T. Papa Constantinou, Philip Huber, Jr., \& Clifford L. Simmang, Fissure-in ano, Charles J. Yea, Daniel T. Dempsey, Andrew S. Klein, John H. Pemberton, Jeffrey H. Peters. Shackelford's Surgery of the Alimentary Tract, Elsevier, 6thedition, 2007, pg. 2038-2044.

16. Kelli M. Bullard \& David A. Rothenberger, Colon, Rectum \& Anus, F. CharlesBrunicardi, Dana K. Anderson, Timothy R. Billiar, David L. Dunn, John G.Hunter, Raphael E. Pollock. Schwartz's Principles of Surgery, Tata Mc Graw Hill, 8th edition, 2005, pg. 1103-1104.

17. R. Bhardwaj, M. C. Parker, Modern perspectives in the treatment of chronic anal fissures.Annals of the Royal College of Surgeons of England. 2007; 89 (5): pg.472-478.

18. BikashMedhi, RamyaSankarnarayanRao, Ajay Prakash, Om Prakash, Lileswar Kaman, PromilaPandhi, Recent advances in the pharmacotherapy of chronic anal fissure

19. I. Lindsey, O. M. Jones, C. Cunningham, N. J. Mc C. Mortensen, Chronic anal fissure.The British journal of surgery. 2004; 91 (3): pg. 270-279.

20. Richard Nelson, A systematic review of medical therapy for anal fissure. Diseases of the colon and rectum. 2004; 47 (4): pg. 422-431.

21. Z. Haq, M. Rahman, R. A. Chowdhury, M. A. Baten, M. Khatun, Chemical sphincterotomy - first line of treatment for chronic anal fissure.Mymensingh Medical Journal. 2005; 14(1): pg. 88-90.

22. E. E. Collins, J. N. Lund, A review of chronic anal fissure management: Techniques in Coloproctology. 2007; 11(3): pg. 209-223.

23. Eveline B. Boeker, M. J. P. MarjanKruijer, Paul C. M. Verbeek, Treatment of chronic anal fissures: Diltiazem or Isosorbidedinitrate as first choice? Nederlands Tijdschrift VoorGeneeskunde. 2011; 155: pg. A2594.

24. K. Bielecki, M. Kolodziejczak, A prospective randomized trial of Diltiazem and Glyceryltrinitrate ointment in the treatment of chronic anal fissure. Colorectal disease the official journal of the Association of Coloproctology of Great Britain and Ireland. 2003; 5(3): pg. 256-257.

25. MasoodJawaid, ZubiaMasood, Manzar Salim, Topical Diltiazem hydrochloride and Glyceryltrinitrate in the treatment of chronic anal fissure. Journal of the College of Physicians and Surgeons Pakistan. 2009; 19(10): pg. 614-617.

26. M. S. Sajid, J. Rimple, E. Cheek, M. K. Baig, The efficacy of Diltiazem and glyceryltrinitrate for the medical management of chronic anal fissure: a meta analysis. International Journal of Colorectal Disease. 2008; 23(1): pg. 1-6.

27. G. F. Nash, K. Kapoor, K. Saeb-Parsy, T. Kunanadam, P. M. Dawson, The long term results of Diltiazem treatment for anal fissure. International Journal of Clinical Practice. 2006; 60(11): pg. 1411-1413.

28. M. S. Sajid, S. Hunte, S. Hippolyte, V. A. Kiri, C. Maringe, M. K. Baig, Comparison of surgical vs chemical sphincterotomy using botulinum toxin for the treatment of chronic anal fissure: a meta analysis. Colorectal disease the official journal of the Association of Coloproctology of 
Great Britain and Ireland. 2008; 10(6): pg. 547-552.

29. D. Simkovic, K. Smejkal, J. Folvarsky, L. Repasky, Treatment of chronic anal fissure with lateral sphincterotomy. Bratislavske LekarskeListy. 1999; 100(2): pg. 89-91.

30. A. M. Saad, A. Omer, Surgical treatment of chronic fissure in ano: a prospective randomized study. East African Medical Journal. 1992; 69(11): pg. 613-615.

31. P. R. Hawley, The treatment of chronic fissure in ano: a trial of methods. The British Journal of Surgery. 1969; 56(12): pg. 915-918.

32. Notaras M.J., The treatment of anal fissure by lateral subcutaneous internal sphincterotomy - A technique and results. British Journal of Surgery. 1971; 58: pg. 96-99.

33. Marvin L. Corman, Anal Fissure, Sydor A. M., McAllister L. Colon and Rectal Surgery. Lippincott Raven, 4th Edition, 1998, pg. 206.

34. Boulos P. B., Araujo J. G. C., Adequate internal sphincterotomy for chronic anal fissure: subcutaneous or open technique? British Journal of Surgery. 1984; 71 (5): pg. 360-362.

35. Udwadia T.E., The prophylaxis of fissure in ano. Indian Journal of Surgery. 1978

36. Scouten W.R. et al., Ischemic nature of anal fissure. British Journal of Surgery. 1996; 83: pg. 63-65.

37. Adriano Tocchi, GianlucaMazzoni, Michelangelo Miccini, Diletta Cassini, EliaBettelli, StefaniaBrozzetti, Total lateral sphincterotomy for anal fissure International Journal of Colorectal Disease. 2004; 19(3): pg. 245-249. 